\title{
The dynamic analysis of load motion during the interaction of wind pressure
}

\author{
Dawid Cekus (10) Paweł Kwiatoń (iD) Tomasz Geisler (i)
}

Received: 20 February 2020/Accepted: 20 August 2020/Published online: 1 September 2020

(C) The Author(s) 2020

\begin{abstract}
This work presents the analysis of the load motion during the interaction of wind pressure. The load was treated as a rigid body, and the rope system model as a non-deformed. The influence of effective area of wind pressure on load motion was considered. The theoretical model of load motion was presented, which may be an universal approach for transporting machines equipped with a rope-lifting system. To define the orientation of the movable Cartesian coordinate system related to the load, Bryant angles were used. An algorithm and computational program were developed to allow for analysis of dynamic phenomena. The initial problem was solved with the use of the ode 45 calculation procedure in the Matlab software on the basis of the Runge-Kutta 4th Order Method. The obtained results were verified with the experimental ones achieved in the wind tunnel and Tracker program. Numerical calculations using commercial software SolidWorks were also presented. In the experiment, the spatial motion of the load was analysed. Experimental tests were carried out for gust
\end{abstract}

D. Cekus · P. Kwiatoń $(\bowtie) \cdot$ T. Geisler

Department of Mechanics and Machine Design

Fundamentals, Czestochowa University of Technology,

Dabrowskiego 73, 42-201 Czestochowa, Poland

e-mail: kwiaton@imipkm.pcz.pl

D. Cekus

e-mail: cekus@imipkm.pcz.pl

T. Geisler

e-mail: geisler@imipkm.pcz.pl of wind and constant temperature and humidity. In addition, the paper presents the application of the proposed method for a load carried by a rotary crane. After taking into account the control functions resulting from the nature of the work of any machine, the formulated model can be a full description of the carried load motion taking into account external forces.

Keywords Wind pressure $\cdot$ Load $\cdot$ Experimental analysis $\cdot$ Dynamics

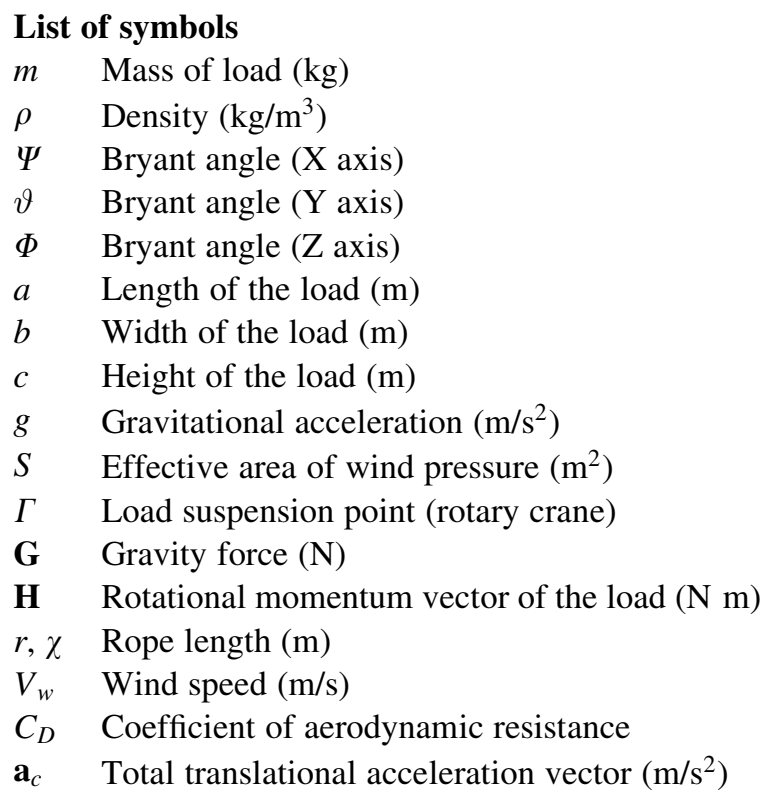


$\mathbf{F}_{n} \quad$ Resultant vector of all acting forces (N)

$\mathbf{M}_{c} \quad$ Momentum vector of all acting forces $(\mathrm{N} \mathrm{m})$

$\mathbf{F}_{r} \quad$ Total vector of the tension in the rope $(\mathrm{N})$

$\mathbf{F}_{w} \quad$ Wind force vector $(\mathrm{N})$

$\omega_{c} \quad$ Angular velocity vector $(\mathrm{rad} / \mathrm{s})$

$\epsilon_{c} \quad$ Angular acceleration vector $\left(\mathrm{rad} / \mathrm{s}^{2}\right)$

$\mathbf{J}_{c} \quad$ Matrix of inertia momentum $\left(\mathrm{kg} \mathrm{m}^{2}\right)$

\section{Introduction}

The impact of external forces, for example, the wind pressure, is essential during the process of load transfer and positioning. Dynamic changes of deflections caused by these forces can trigger load positioning errors or, in extreme cases, machine instability. However, the impact of external factors, including wind pressure, is a phenomenon often neglected during an analysis of the work cycles of transport equipment. The machine instability caused by too strong load fluctuations caused by wind [1,2], can be the result of such neglecting phenomenon.

In the literature, several works on the subject of strength analysis, load dynamics or trajectory optimization can be found. Research on transport machines primarily concerns issues related to rotary cranes [3-10], tower cranes [11, 12] and gantry cranes [13-20].

Works [3-5] concern modelling of rotary crane load dynamics, taking into account various transport processes and positioning. The load positioning process under the influence of kinematic forcing [3] and the impact of external forces on load deflections during crane working cycle [4] were analysed. The dynamics of the lifted load and mobile crane with consideration of the flexibility of support system on crane stability [5] was also investigated. Truck crane stability was analysed in [6], where the $\mathrm{CAD} / \mathrm{CAE}$ program and the neural network system were used to determine the values of the vertical reactions of the base. CAD/CAE programs, which example can be SolidWorks, are as well used for strength and vibration analyses [7-9]. Article [7] presents the strength analysis of the telescopic boom of the mobile crane. The presented approach can provide guidelines for the optimal design of telescopic parts and other structures with local stresses in the contact zone. In [8], CAE tools were used to determine the frequency of the loading crane. The obtained results were verified by experimental research. Work [9] presents a free vibration analysis of a mobile crane taking into account load configuration changes. Analysis of the vibrations of the crane is also depicted in [10], where a mathematical description with the flexibility of individual structure members was presented.

In the works related to tower cranes, the most common topics discussed are dynamic analysis $[11,12]$. The dynamic reliability induced by wind loading was investigated in [11]. The resonance frequencies of the analysed crane were determined and the influence of wind on displacements of respective nodes was discussed. Whereas in work [12], an experimental analysis of load motion in the frequency domain was presented. A method of controlling transferred load oscillations was also introduced.

Gantry and overhead cranes are one of the most common devices used for transporting cargo [13]. The problem of load dynamics during transport and positioning was analysed in the works [14-16]. In [14], the vibration control of the gantry crane with a suspended load was presented. Different trolley kinematic configurations on load oscillations were analysed in [15]. The finite element method was used to determine the forces acting on the device due to the load transportation process. A theoretical model of a load carried by overhead crane using Lagrange equation of the second kind was shown in [16]. The simulation model, which was developed using Matlab software, allowed the trolley and payload trajectory to be determined. Due to the fact that overhead cranes are used in external conditions, several works analyse the impact of external forces (e.g. wind pressure) on the machine's working cycle [17-20]. A dynamical model of a gantry crane and its control system was presented in [17]. Issues related to the load operation and its positioning under the wind disturbances were analysed. Hence, the experimental tests were conducted in the motionless state. The problem of payload deflections and positioning of the load has been widely described in the works [18-20]. These articles used neural networks [18], output-based command shapers [19] and a control scheme with command smoother [20]. In addition, the verification process was carried out using experimental tests. 
In the literature of the subject, one can find works that do not strictly relate to the load transport. However, they are a valuable complement to the topic of rigid body motion, which includes the load motion. The motion of rigid bodies as a motion of the mathematical and physical pendulum is shown in works [21-27]. The deformability of the rope system was included in the paper [21]. Whereas in the work [22], the motion of rigid bodies connected by nondeformable ropes is presented. The harmonical and kinematical excite dynamical system provided by spring pendulum is analysed in [23]. In addition, the proposed model enables the determination of resonances using the multi-scale (MS) method. In work [24], MS method is used to analyse a non-linear system with two degrees of freedom. Transport of energy between modes of vibration is also presented. The problem of spring pendulum nonlinear vibrations and resonances has also been extensively described in articles [25, 26]. In both of these works, the asymptotic method was used for analytical calculations. The spring motion equations were obtained using the 2 nd type Lagrange's equations.

This paper presents the analysis of the load motion during its free motion under the interaction of wind pressure. The results obtained on the basis of analytical and numerical simulations have been compared and verified with the experimental results. The application of the proposed analytical method has been also presented on the example of a rotary crane working cycle. Part of this research was presented at the 15th International Conference Dynamical Systems Theory and Applications (DSTA2019) [28].

\section{Research methods}

Three research methods that allow for motion analysis of the load during the interaction of the wind pressure have been examined in this work: an analytical approach using the Matlab environment, numerical calculations in the SolidWorks program and experimental research in the low-speed wind tunnel.

The model, shown in Fig. 1, was developed on the basis of the following assumptions. The load was treated as a rigid body, attached at point $O$ on a nondeformable rope with fixed length $r$. The load motion has been treated as the spatial motion. The direction of wind force $\left(\mathbf{F}_{w}\right)$ was adopted from experimental tests

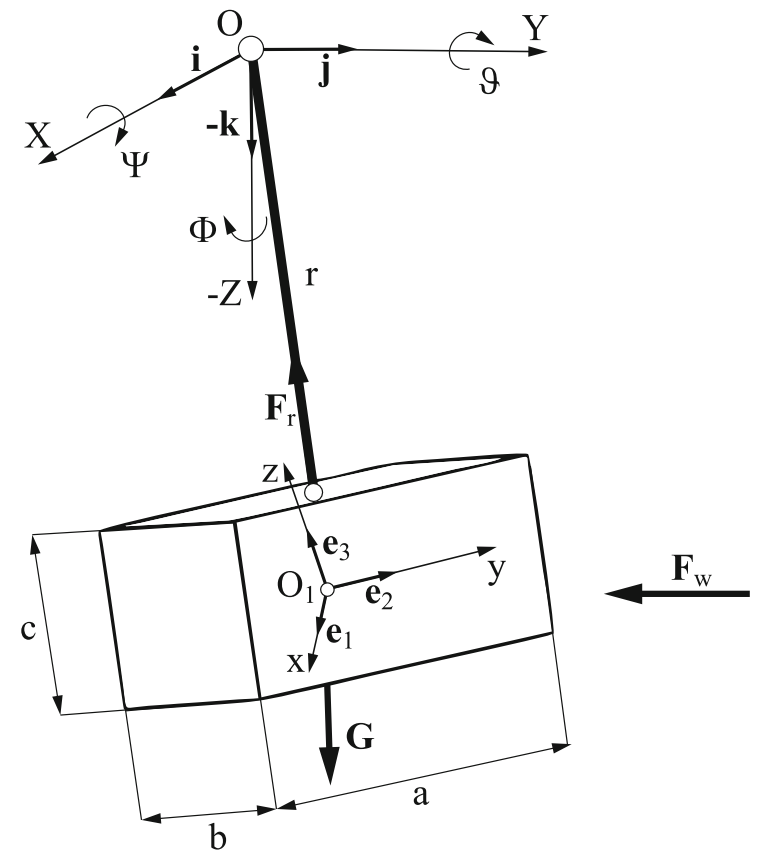

Fig. 1 The dynamic model used for an analytical approach

performed in the wind tunnel. Aerodynamic drag has been omitted in numerical simulations due to the negligible impact on analysed motion in application (rotary cranes). Due to the adopted assumptions, two coordinate systems have been introduced: $O X Y Z-$ inertial system, $O_{1} x y z$-movable system connected with the load centre of mass. In addition, Bryant's angles $(\Psi, \vartheta, \Phi)$ were introduced in an analytical approach to determine the position of the load [29].

\subsection{Analytical approach}

The general motion of the rigid body can be presented as a combination of translational motion relative to the origin of the global coordinate system (1) and rotational motion relative to the load's centre of mass (2) $[17,30-35]$ :

$$
\begin{aligned}
& m \mathbf{a}_{c}=\mathbf{F}_{n}, \\
& \frac{d}{d t} \mathbf{H}=\mathbf{M}_{c},
\end{aligned}
$$

where $m$ is the mass of the transferred load, $\mathbf{a}_{c}$ is the total translational acceleration vector of the centre of mass of load in the inertial coordinate system, $\mathbf{M}_{c}$ is the momentum vector of all forces acting on the system with respect to the centre of mass, $\mathbf{H}$ is 
the rotational momentum vector of the load with regard to its centre of mass, $\mathbf{F}_{n}$ is the resultant force vector of all forces acting on the system.

The rotational momentum vector of the load $\mathbf{H}$ with respect to the continuous mass density is given by [32]:

$$
\mathbf{H}=\int \mathbf{r} \times \mathbf{v} d m
$$

where $\mathbf{r}$ is a position vector from reference point with respect to $d m$ element and $\mathbf{v}$ is a velocity vector.

Omitting the air resistance, the resultant force vector $\mathbf{F}_{n}$ may be shown as [36]:

$$
\mathbf{F}_{n}=\mathbf{F}_{r}+\mathbf{G}+\mathbf{F}_{w},
$$

where $\mathbf{F}_{r}$ is the total vector of the tension in the rope, $\mathbf{G}$ is the load's gravity force, and $\mathbf{F}_{w}$ is the wind power.

Taking into account the angular velocity vector:

$$
\omega_{c}=\omega_{1} \mathbf{e}_{1}+\omega_{2} \mathbf{e}_{2}+\omega_{3} \mathbf{e}_{3},
$$

matrix of inertia momentum $\mathbf{J}_{c}$ and the derivative of the absolute angular momentum of the load in the inertial system:

$$
\frac{d}{d t} \mathbf{H}=\frac{\tilde{d}}{d t} \mathbf{H}+\omega_{c} \times \mathbf{H}
$$

the rotational motion (2) can be represented as [32]:

$$
\begin{aligned}
& M_{1}=J_{1} \epsilon_{1}+\left(J_{3}-J_{2}\right) \omega_{2} \omega_{3}, \\
& M_{2}=J_{2} \epsilon_{2}+\left(J_{1}-J_{3}\right) \omega_{3} \omega_{1}, \\
& M_{3}=J_{3} \epsilon_{3}+\left(J_{2}-J_{1}\right) \omega_{1} \omega_{2},
\end{aligned}
$$

where the $O_{1} x y z$ is the coordinate system with the principal axes of intertia and $\frac{\tilde{d}}{d t}$ is a derivative in a movable (relative) coordinate system.

Based on works [3, 5], vector equation (1) may be presented as:

$$
\begin{aligned}
& \ddot{X}=-a_{O_{x}}+\frac{F_{w_{x}}}{m}+\frac{X}{r^{2}} \Upsilon, \\
& \ddot{Y}=-a_{O_{y}}+\frac{F_{w_{y}}}{m}+\frac{Y}{r^{2}} \Upsilon, \\
& \ddot{Z}=a_{O_{z}}+g+\frac{F_{w_{z}}}{m}+\frac{Z}{r^{2}} \Upsilon,
\end{aligned}
$$

where

$$
\begin{aligned}
\Upsilon= & r \ddot{r}+\dot{r}^{2}+X a_{O_{x}}+Y a_{O_{y}}-Z\left(a_{O_{z}}+g\right)+ \\
& -\left(\dot{X}^{2}+\dot{Y}^{2}+\dot{Z}^{2}\right) .
\end{aligned}
$$

The impact of wind pressure acting on the load can be represented using a formula (14) for aerodynamic resistance $[11,37]$ :

$$
\left|\mathbf{F}_{w}\right|=\frac{1}{2} \rho S V_{w}^{2} C_{D}
$$

where $\rho$ is the air density, $S$ is the effective area of wind pressure, $V_{w}$ is the wind speed, $C_{d}$ is the dimensionless coefficient of aerodynamic resistance.

The parameter of effective area wind loading has been extensively described in the works [36, 38]. The final formula for calculating the effective area parameter $S$ can be represented in the form:

$$
S=a b \cos \left(\gamma_{1}\right)+a c \cos \left(\gamma_{2}\right)+b c \cos \left(\gamma_{3}\right),
$$

where $a, b, c$ are the dimensions of the load and $\gamma_{1}, \gamma_{2}$, $\gamma_{3}$ are angles between normal vectors and surface on which wind pressure has influence.

Considering the above relationships, a system of six ordinary differential equations of the second order was obtained [5, 34]:

$$
\mathbf{D} \ddot{\Omega}=\mathbf{E},
$$

where $\mathbf{E}$ is a vector of generalized angular velocities of the rigid body and accelerations of the rope suspension point, D is a matrix dependent on Bryant angles, geometric parameters of the body and its density and $\ddot{\Omega}$ is a vector of unknown Bryant angles accelerations and inertial system coordinates which can be presented in the form:

$$
\ddot{\Omega}=\left[\begin{array}{c}
\ddot{X} \\
\ddot{Y} \\
\ddot{Z} \\
\ddot{\Psi} \\
\ddot{\Theta} \\
\ddot{\Phi}
\end{array}\right]
$$

To solve the initial problem of load motion, the system of equations (16) was reduced to the system of twelve differential equations of the first order [33, 39]. All symbolic operations necessary to formulate the problem of initial load motion were performed using the 
Wolfram Mathematica package. The initial problem has been solved using ode 45 procedure available in Matlab/Simulink program [3, 4, 36, 39].

\subsection{Experimental research}

The load was suspended using a cable, which properties correspond to a non-deformable rope [4]. The test stand consisted of a wind tunnel with dimensions $0.6 \mathrm{~m} \times 0.6 \mathrm{~m} \times 3.0 \mathrm{~m}$, fan with radius $0.35 \mathrm{~m}$, and anemometer UT362, which made it possible to determine the value of wind force as a function of time. The devices that allowed to record the experimental research included: Nikon D610 camera with Nikkor 24-70 lens and Nikon D90 with Nikkor 17-55 lens with a minimum aperture value both lens of $2.8^{\circ}$ (Figs. 2, 3).

During the experiment, wind pressure acts only along $\mathrm{X}$ axis. The spatial motion of the load was considered. Tests were carried out for various inflow velocities (from 0 to $4.5 \mathrm{~m} / \mathrm{s}$ ) and constant and controlled temperature and humidity [4, 40]. The video analysis was performed in the Tracker program (Fig. 4), which allows tracking the coordinates of vertices and the mass centre of the load.

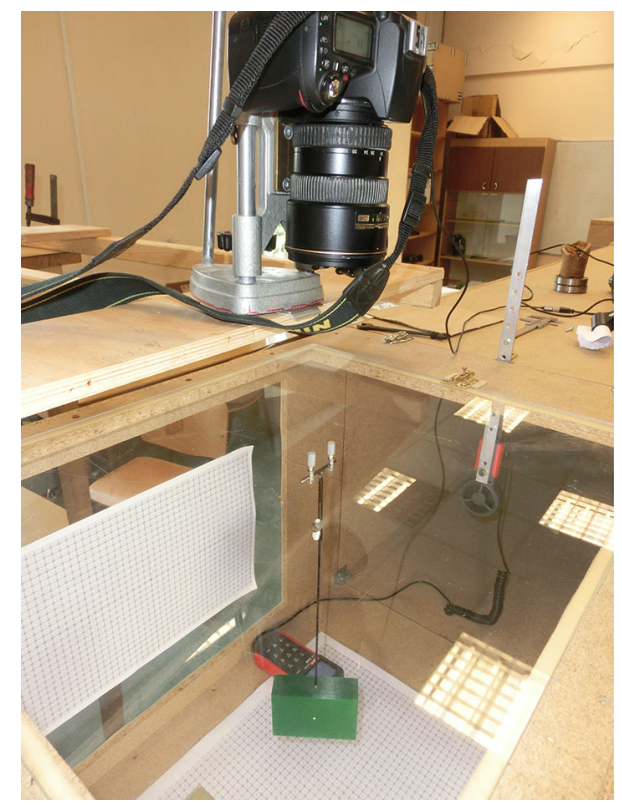

Fig. 2 Experimental test stand (top view)

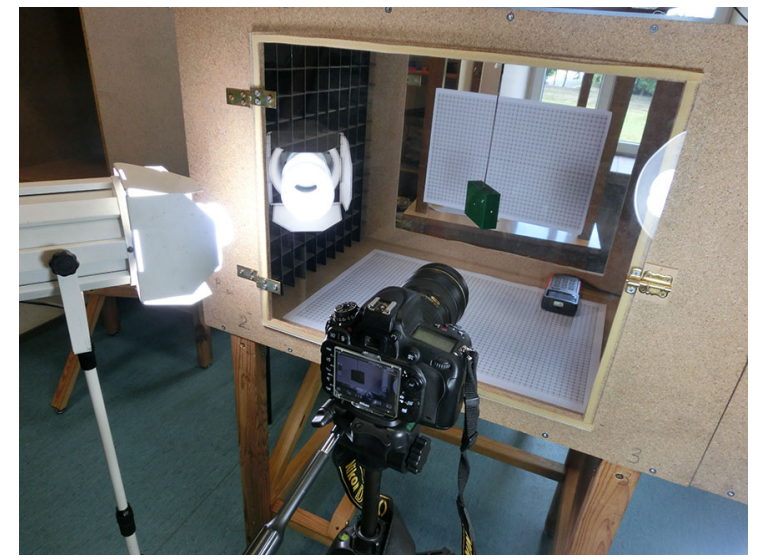

Fig. 3 Experimental test stand (rear view)

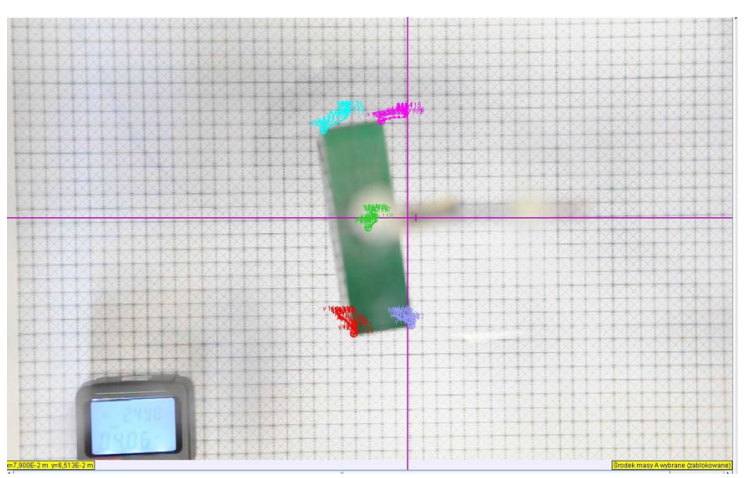

Fig. 4 Video analysis using the tracker program

\subsection{Numerical simulations using the SolidWorks package}

The last part of this work concerns the study of the load motion using the Motion module of SolidWorks package. Motion simulation provides complete, quantitative information about the kinematics (including position, velocity, and acceleration) and the dynamics (including joint reactions, inertial forces, and power requirements) of all components of a moving mechanism. Often of great additional importance, the results of motion simulation can be obtained virtually at no additional time expense, because everything needed to perform motion simulation has been defined in the CAD assembly model already, and just needs to be transferred to the Motion module [41].

The analysed model is an assembly consisting of three parts: a rigid body (Fig. 5:1), a non-deformable cable (Fig. 5:2) and the base on which the rope was suspended. Due to limitations in the SolidWorks 


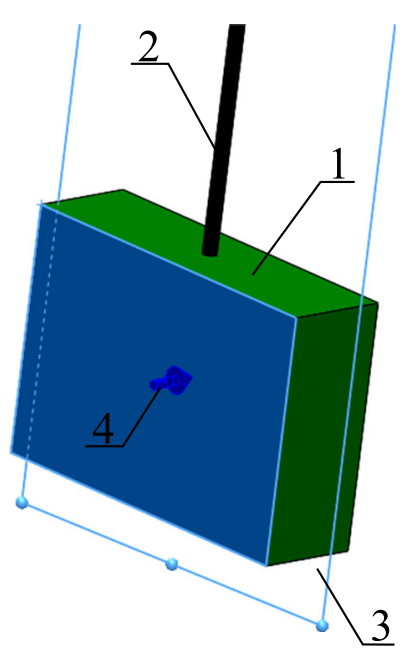

Fig. 5 Analysed model in SolidWorks motion (1-rigid body, 2-cable, 3-wind acting plane, 4-wind power)

program, a constant surface area (Fig. 5:3) on which wind power (Fig. 5) has effect was adopted.

\section{Sample results of performed investigations}

In this work, the impact of gusts on the load behaviour in stationary state was investigated. The obtained simulation results were compared with experimental results, which were conducted in a low-speed wind tunnel. The results are presented in the form of load's centre of mass coordinates changes as a function of time (Figs. 6, 7, 8, 9). The parameters of the calculation model are presented in Table 1. Load model used during experimental tests was made using 3D printing method. The coefficient of aerodynamic drag was chosen according to the literature data [42-44].

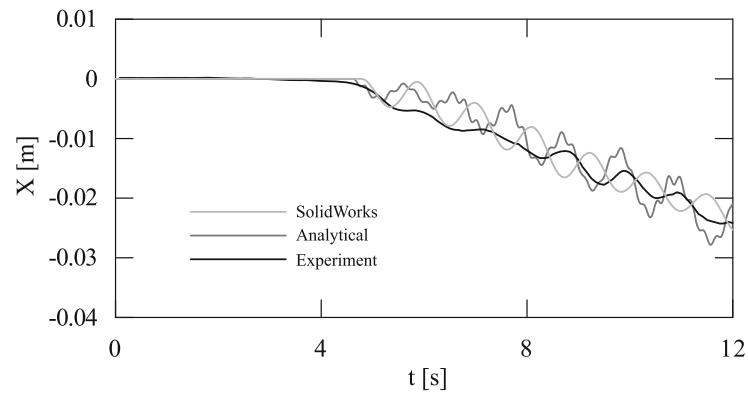

Fig. 6 Time course of the X coordinate of load's centre of mass

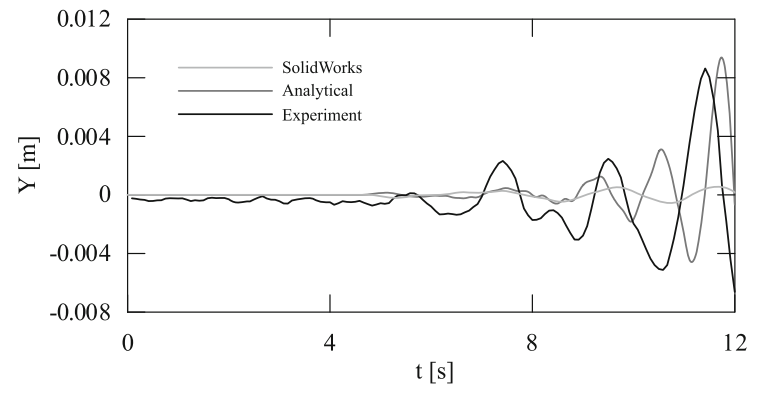

Fig. 7 Time course of the Y coordinate of load's centre of mass

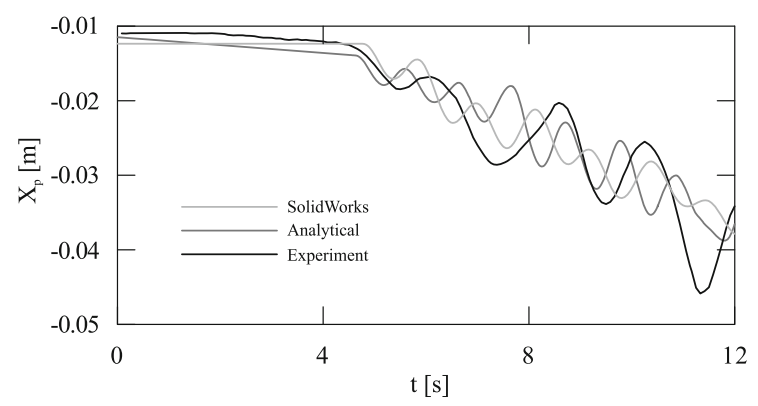

Fig. 8 Time course of the $X$ coordinate of one selected vertex of load

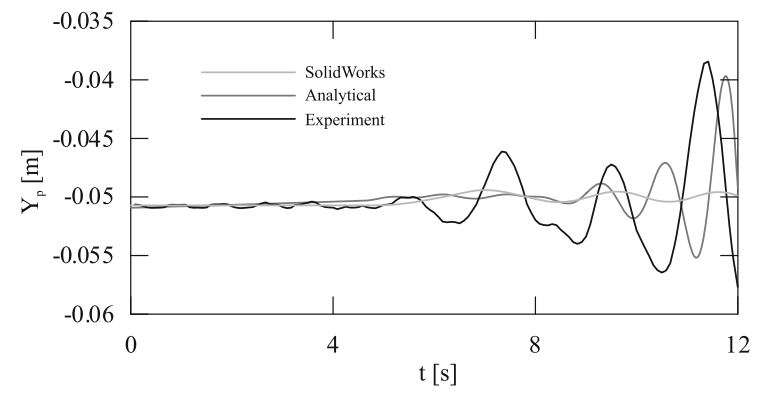

Fig. 9 Time course of the $\mathrm{Y}$ coordinate of one selected vertex of load

Table 1 Parameters of the calculation model

\begin{tabular}{llll}
\hline $\begin{array}{l}\text { Load } \\
\text { mass } \\
(\mathrm{kg})\end{array}$ & $\begin{array}{l}\text { Rope } \\
\text { length } \\
(\mathrm{m})\end{array}$ & $\begin{array}{l}\text { Load } \\
\text { dimensions } \\
(\mathrm{m})\end{array}$ & $\begin{array}{l}\text { Aerodynamic } \\
\text { resistance } \\
\text { coefficient }\end{array}$ \\
\hline 0.133 & 0.28 & $0.1 \times 0.03 \times 0.07$ & 1.05 \\
\hline
\end{tabular}

The analysed load had a cuboid shape and a mass equal to $0.133 \mathrm{~kg}$. The wind speed increased over time from $0 \mathrm{~m} / \mathrm{s}$ until it reached $5.3 \mathrm{~m} / \mathrm{s}$ (in $12 \mathrm{~s}$ ). The swing angle relative to the $\mathrm{X}$ axis was three degrees. 
Coordinate changes caused by wind force of load's centre of mass (Figs. 6,7) and one selected vertex of load (Figs. 8, 9) are presented. The percentage of variation of $\mathrm{X}$ load's mass centre coordinate as a function of time is also shown in Fig. 10. The differences between the numerical calculations and the results of the experiment are caused among others by the omission of the air damping in the numerical studies.

Based on the obtained results, a similar trend of $\mathrm{X}$ coordinate variations can be seen for all research methods. The larger differences were observed for Y coordinate, when wind speed exceeds $4 \mathrm{~m} / \mathrm{s}$. At this moment, the rotational motion of the load was noticed. The phenomenon of spatial motion better reflected the analytical approach than the numerical simulation performed in SolidWorks software. It is caused by taking into account the variable surface area induced by wind in the analytical approach. The percentage differences of variation (Fig. 10) do not give an explicit determination as to which method gives results closer to the experiment. However, comparing displacements of the load, one can assume that the analytical approach better presents the three-dimensional motion of the load.

\section{Application of the analytical method for load motion carried by rotary crane}

As an application of the developed analytical method, the load motion during the working cycle of the mobile crane was presented. Taking into account kinematic excitations resulting from the nature of work of this type of lifting equipment (Fig. 11), formulas (10, 11 and 12) can be presented as follows:

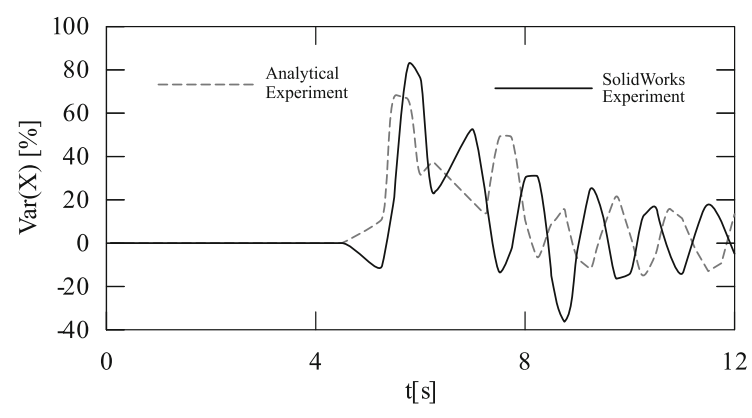

Fig. 10 Percentage of variation of the $X$ coordinate of load's centre of mass

$$
\begin{aligned}
& \ddot{\kappa}=-a_{\Gamma_{x}}+\frac{F_{w_{x}}}{m}+\frac{\kappa}{\chi^{2}} \Xi, \\
& \ddot{\tau}=-a_{\Gamma_{y}}+\frac{F_{w_{y}}}{m}+\frac{\tau}{\chi^{2}} \Xi, \\
& \ddot{v}=a_{\Gamma_{z}}+g+\frac{F_{w_{z}}}{m}+\frac{v}{\chi^{2}} \Xi,
\end{aligned}
$$

where $a_{\Gamma_{x}}, a_{\Gamma_{y}}, a_{\Gamma_{z}}$ are components of the crane's boom tip acceleration $\kappa, \tau, v$ are generalized boom tip coordinates, $\chi$ is a length of the rope and $\Xi$ takes the form:

$$
\begin{aligned}
\Xi= & \chi \ddot{\chi}+\dot{\chi}^{2}+\kappa a_{\Gamma_{x}}+\tau a_{\Gamma_{y}}-v\left(a_{\Gamma_{z}}+g\right)+ \\
& -\left(\dot{\kappa}^{2}+\dot{\tau}^{2}+\dot{v}^{2}\right) .
\end{aligned}
$$

The kinematic part of the load analysis carried by rotary crane concerned the determination of motion parameters of the rotary crane's boom end (point $\Gamma$ ) which was further described in $[5,45]$. The main system of the mobile crane consists of a two-member telescopic jib and a pulley system. For the purposes of this work, the following assumptions were made $[5,36]$ :

- Crane main elements were treated as a nondeformable bodies;

- The rotary crane was placed on a non-deformable base;

- Load was treated as a rigid body attached at point $\Gamma$ on a stable, static rope with variable length $\chi$;

- Wind pressure was related only to the dynamic part (the wind impact on crane main system was omitted);

- Wind pressure direction was adopted as constant (acting along the $\mathrm{X}$ direction of the global coordinate system);

- Wind speed simulating wind gusts (Fig. 12) was determined on the basis of real data [46].

The following rectangular coordinate systems have been introduced in relation to the above assumptions [36]:

- $O_{1} x_{1} y_{1} z_{1}$-inertial system related to the rotary crane chassis;

- $\mathrm{O}_{2} x_{2} y_{2} z_{2}$-movable system related to the jib support;

- $\quad \Gamma \kappa \tau v-$ movable system related to the jib end $(\Gamma)$;

- $O X Y Z$ - movable system related to the load centre of mass. 


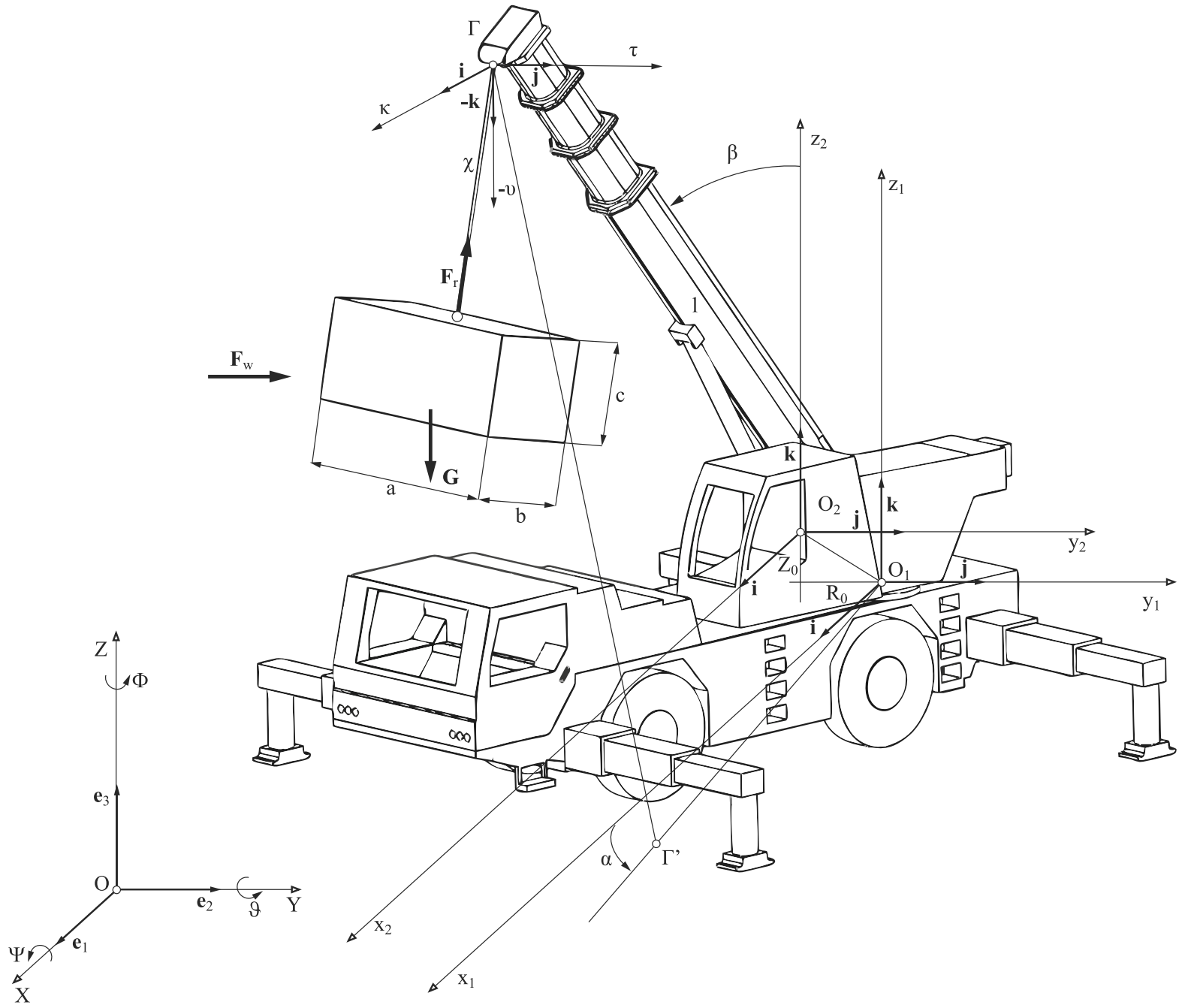

Fig. 11 The model of the analysed system (rotary crane and transferred load)

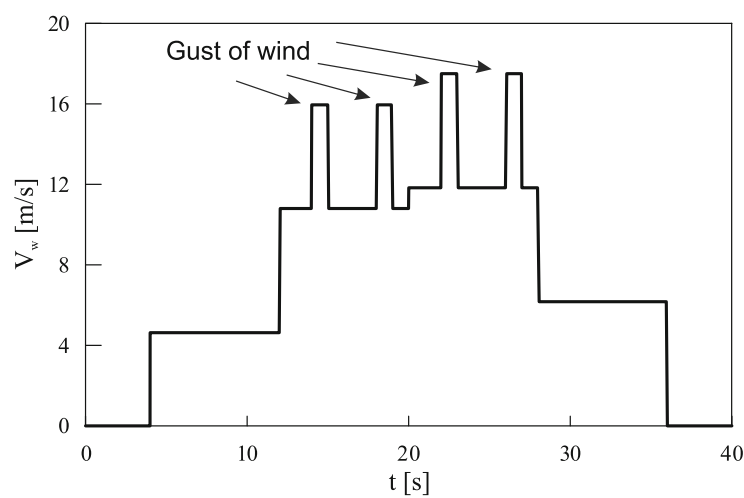

Fig. 12 Time course of wind speed
In addition, the following coordinates have been identified: $l$-jib length, $\beta$-angle of jib inclination, $\chi$-rope length, $\alpha$ - crane rotation angle, $Z_{0}$ and $R_{0}$ coordinates of jib rotation point $\left(\mathrm{O}_{2}\right)$. Motion of the jib end (kinematic part) is caused due to changes of generalized coordinates (control function): $l, \alpha, \beta$ and $\chi$ (Fig. 13).

The presented numerical simulation concerned the initial problem where the load was hanging freely. The control functions (Fig. 14) were introduced in the form of trapezoidal impulses and resulted from:

- Platform rotational motion with a telescopic boom $(\alpha)$ - the motion starts at $0 \mathrm{~s}$ and takes $10 \mathrm{~s}$, the maximum velocity equals $0.2 \mathrm{rad} / \mathrm{s}$ (Fig. 14a), 


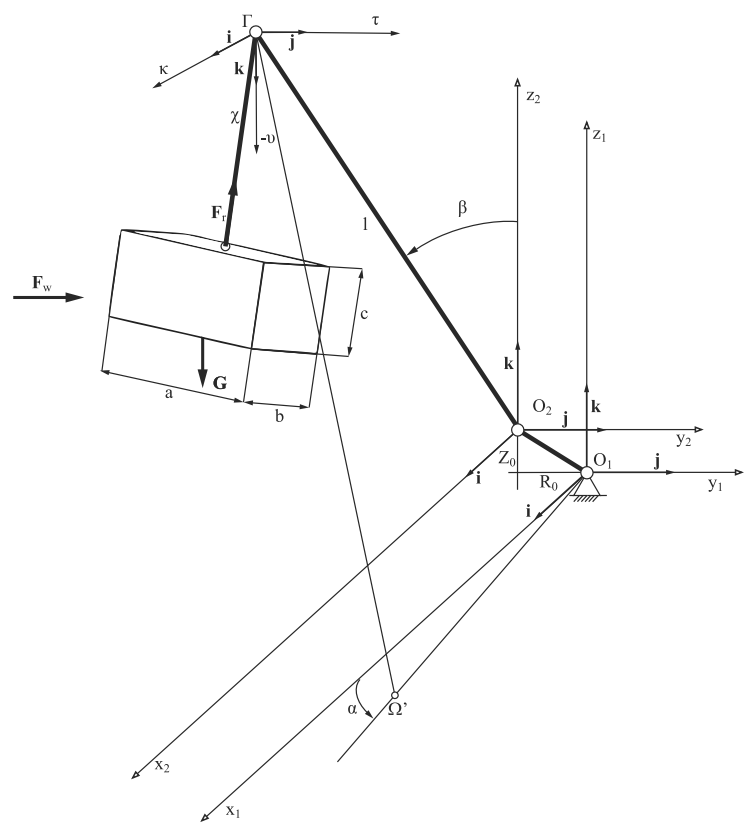

Fig. 13 Coupled kinematic-dynamic model of load motion

- Working stroke control of the system of two hydraulic actuators responsible for changing the overall length of the jib $(l)$ - start of the motion in $10 \mathrm{~s}$ and lasts for $10 \mathrm{~s}$, the maximum velocity equals $0.1 \mathrm{~m} / \mathrm{s}$ (Fig. 14b),

- Working stroke control of the hydraulic actuator responsible for changing the boom inclination angle $(\beta)$-the forcing takes $10 \mathrm{~s}$ and ends at $30 \mathrm{~s}$, the maximum velocity equals $0.025 \mathrm{rad} / \mathrm{s}$ (Fig. 14c),

- Winch operation control $(\chi)$-rope extension starts at $30 \mathrm{~s}$ and lasts $10 \mathrm{~s}$, the maximum velocity equals $0.15 \mathrm{~m} / \mathrm{s}$ (Fig. 14d).

In the control functions, the start-up and braking motion lasted half a second. The total time of the simulations included 40-s forced motion of the analysed system. The parameters of the rotary crane calculation model are presented in Table 2. Initial values of generalized coordinates were: $\alpha=90^{\circ}$, $\beta=20^{\circ}, l=8 m, \chi=3 m, Z_{0}=1.55$ and $R_{0}=1.25 m$.

The response of the system to the assumed control functions (Fig. 14) was obtained in the form of trajectories projections of the load's mass centre in the rotation (XY) and lifting (XZ and YZ) planes (Figs. 15, 16, 17). The performed investigations allowed to determine the impact of wind pressure on the trajectory of the load carried by a rotary crane.
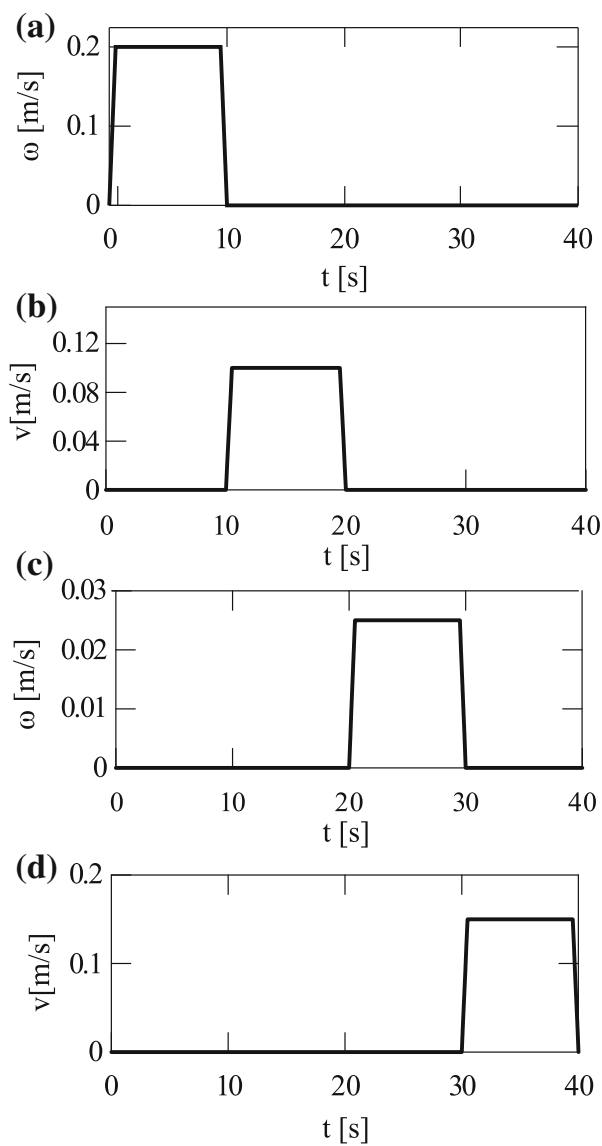

Fig. 14 Control functions: a rotation of platform, b boom length, $\mathbf{c}$ boom inclination angle, $\mathbf{d}$ winch operation

Table 2 Parameters of the rotary crane calculation model

\begin{tabular}{llll}
\hline $\begin{array}{l}\text { Load } \\
\text { mass } \\
(\mathrm{kg})\end{array}$ & $\begin{array}{l}\text { Rope } \\
\text { length } \\
(\mathrm{m})\end{array}$ & $\begin{array}{l}\text { Load } \\
\text { dimensions } \\
(\mathrm{m})\end{array}$ & $\begin{array}{l}\text { Aerodynamic } \\
\text { resistance } \\
\text { coefficient }\end{array}$ \\
\hline 1200 & 3 & $2.21 \times 0.85$ & 1.05 \\
\hline
\end{tabular}

On the basis of the obtained results of the load motion, it can be seen that the wind has an impact on the trajectory of the carried load and should not be neglected when analysing transport equipment exposed to such interactions. The highest deflections of the load caused by wind were noticed in the rotation plane (XY) along the axis of wind direction. For the first control function (rotation of crane platform) there were no differences in the load trajectory. In this time interval, the wind speed did not exceed $5 \mathrm{~m} / \mathrm{s}$. These 


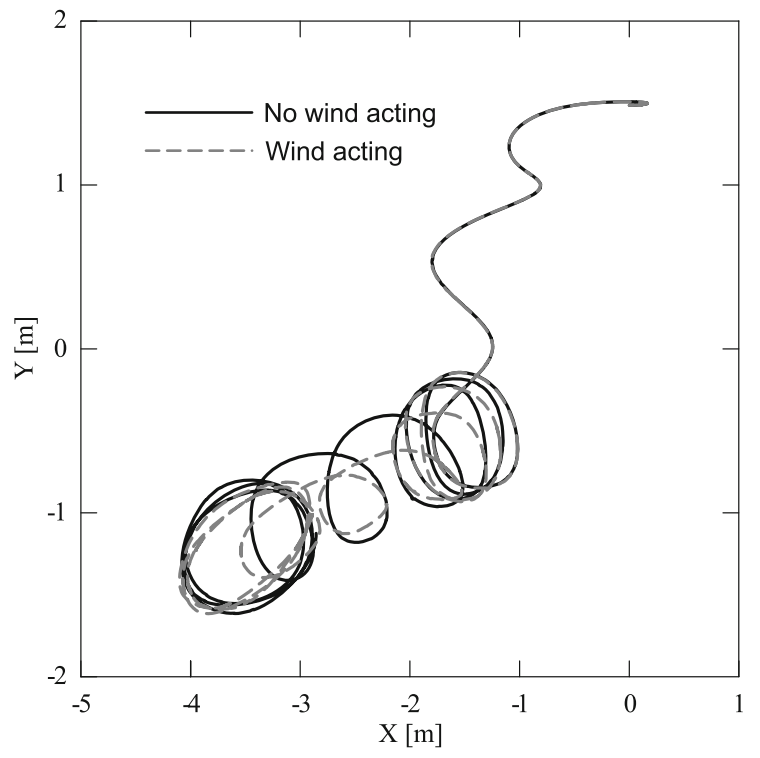

Fig. 15 Trajectory projections of the load's centre of mass in the rotation plane (XY)

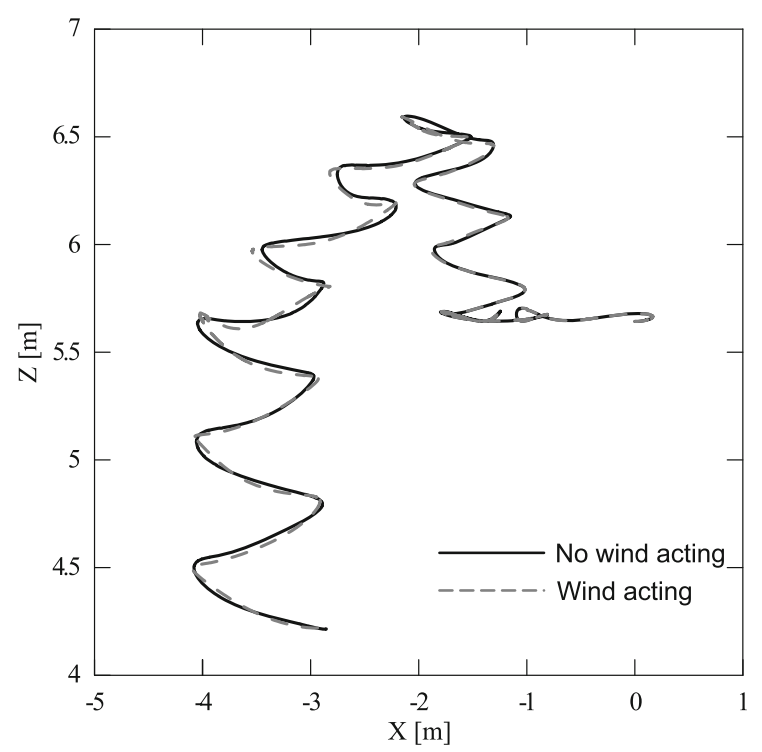

Fig. 16 Trajectory projections of the load's centre of mass in one of the lifting planes (XZ)

results confirm the Polish standards of cranes safety and operation. When wind speed does not exceed $10 \mathrm{~m} / \mathrm{s}$, work can be done normally. When wind speed passes $17 \mathrm{~m} / \mathrm{s}$, the crane should be anchored and a load should be reduced by half. The limit value of wind speed is $20 \mathrm{~m} / \mathrm{s}$ - work above this value is disallowed. The largest load deflections due to the

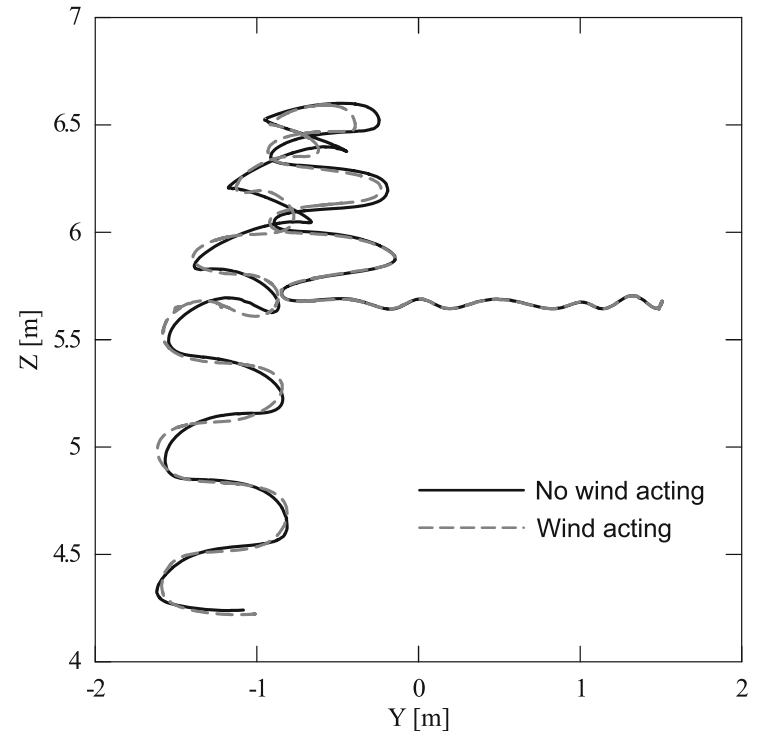

Fig. 17 Trajectory projections of the load's centre of mass in one of the lifting planes (YZ)

wind pressure were noticed for two control functions: boom length and inclination angles changes. During these functions, the wind was blowing at the highest speed, where gusts of wind reached $18 \mathrm{~m} / \mathrm{s}$. Deflection of the payload induced by such a high wind speed might even lead to stability loss of a rotary crane.

\section{Conclusions}

The paper presents an analysis of load motion with the interaction of wind pressure. Load motion was analysed through three approaches: analytical using Matlab software, numerical with the use of SolidWorks packages and experimental test. The mathematical model developed in analytical approach, after taking into account kinematic forcing resulting from the nature of machine work, can be a full description of the motion of the load carried by any transporting device. The load was treated as a rigid body suspended on a non-deformable rope. Combination of translational and rotational motion was used to present the load motion. Bryant angles were used to determine the load trajectories and deflections. Wind pressure acting on the load was included as an aerodynamic drag formula. Initial problem of load motion was solved using ode45 procedure in Matlab software. The experimental research was conducted in a low-speed 
wind tunnel. Load motion has been limited in such a way as to remind the pendulum motion. The obtained experimental data made it possible, with the use of Tracker program, to present the trajectory of the mass centre and vertices of the analysed body. During the experimental test, the irregular behaviour of the load was noticed when the wind speed exceeds $4 \mathrm{~m} / \mathrm{s}$. The results obtained numerically present a similar trend of coordinates changes with the results obtained in experimental studies. The disadvantage of numerical simulations using the SolidWorks program is that the variable effective surface area is not included. Based on the obtained results, the correctness of the analytical approach can be stated. Numerical tests performed in the SolidWorks software do not show the characteristic spatial motion of the rigid body, especially the rotational motion towards $\mathrm{Y}$ direction. Application of a given analytical research approach was also presented. The results confirmed the recommendations regarding crane safety. When the wind speed does not exceed $10 \mathrm{~m} / \mathrm{s}$, cargo deflections are negligible. However, if the wind speed is higher, deflections also increase, which can even cause the instability of the machine. The mathematical model presented in this work will be further developed by taking into account air resistance or rope deformability.

Acknowledgements This work has been carried out within statutory research of the Department of Mechanics and Machine Design Fundamentals of Czestochowa University of Technology.

\section{Compliance with ethical standards}

Conflict of interest The authors declare that they have no conflict of interest.

Open Access This article is licensed under a Creative Commons Attribution 4.0 International License, which permits use, sharing, adaptation, distribution and reproduction in any medium or format, as long as you give appropriate credit to the original author(s) and the source, provide a link to the Creative Commons licence, and indicate if changes were made. The images or other third party material in this article are included in the article's Creative Commons licence, unless indicated otherwise in a credit line to the material. If material is not included in the article's Creative Commons licence and your intended use is not permitted by statutory regulation or exceeds the permitted use, you will need to obtain permission directly from the copyright holder. To view a copy of this licence, visit http://creativecommons.org/licenses/by/4.0/.

\section{References}

1. Klinger C (2014) Failures of cranes due to wind induced vibrations. Eng Fail Anal 43:198-220. https://doi.org/10. 1016/j.engfailanal.2013.12.007

2. Frendo F (2016) Gantry crane derailment and collapse induced by wind load. Eng Fail Anal 66:479-488. https:// doi.org/10.1016/j.engfailanal.2016.05.008

3. Cekus D, Kwiaton P (2018) Analysis of the motion of the load carried by a laboratory mobile crane. In: Proceedings of 24th international conference engineering mechanics 2018, vol 24, pp 137-140. https://doi.org/10.21495/91-8-137

4. Cekus D, Gnatowska R, Kwiatoń $P$ (2018) Influence of wind on the movement of the load. J Phys Conf Ser 1101:012005. https://doi.org/10.1088/1742-6596/1101/1/012005

5. Posiadała B (1997) Influence of crane support system on motion of the lifted load. Mech Mach Theory 32:9-20. https://doi.org/10.1016/0094-114x(96)00044-4

6. Kacalak W, Budniak Z, Majewski M (2018) Computer Aided Analysis of the Mobile Crane Handling System Using Computational Intelligence Methods. In: Silhavy R., Silhavy P., Prokopova Z. (eds) Applied Computational Intelligence and Mathematical Methods. CoMeSySo (2017) Advances in intelligent systems and computing, vol 662. Springer, Cham, pp 250-261

7. Savkovic M, Gasic M, Pavlovic GV, Bulatovic R, Zdravkovic N (2014) Stress analysis in contact zone between the segments of telescopic booms of hydraulic truck cranes. Thin-Walled Struct 85:332-340. https://doi.org/10.1016/j. tws.2014.09.009

8. Dunaj P, Niesterowicz B, Szymczak B (2019) Loader crane modal analysis using simplified hydraulic actuator model. In: Gapiński B, Szostak M, Ivanov V (eds) Advances in manufacturing II. Manufacturing. Lecture notes in mechanical engineering. Springer, Cham, pp 70-80

9. Geisler T (2018) Free vibration analysis of a DST-0285 truck crane considering changes in the system load configuration. MATEC Web Conf 157:03005. https://doi.org/10. 1051/matecconf/201815703005

10. Jarzębowska E, Urbaś A, Augustynek K (2019) Analysis of influence of a crane flexible supports, link flexibility, and joint friction on vibration associated with programmed motion execution. J Vib Eng Technol. https://doi.org/10. 1007/s42417-019-00186-1

11. Jiang H, Li Y (2016) Dynamic reliability analysis of tower crane with wind loading. IOP Conf Ser Mater Sci Eng 677:052031. https://doi.org/10.1088/1757-899X/677/5/ 052031

12. Capkova R, Kozaikova A, Minar M (2019) Experimental modelling and control of a tower crane in the frequency domain. Strojnícky časopis J Mech Eng 69:17-26

13. Sowa L, Skrzypczak T, Kwiaton P (2018) The effect of the gantry crane beam cross section on the level of generated stresses. MATEC Web Conf 157:02047. https://doi.org/10. 1051/matecconf/201815702047

14. Grazioso S, Di Gironimo G, Singhose W, Siciliano B (2017) Input predictive shaping for vibration control of flexible systems. In: 2017 IEEE conference on control technology and applications, August 27-30, 2017, Kohala Coast, USA. https://doi.org/10.1109/ccta.2017.8062480 
15. Solazzi L, Cima M (2019) Structural dynamics of big gantry crane subjected to different trolley move laws. J Phys Conf Ser 1264:012046. https://doi.org/10.1088/1742-6596/1264/1/012046

16. Enin SS, Omelchenko EY, Fomin NV, Beliv AV (2018) Overhead crane computer model. IOP Conf Ser Mater Sci Eng 327:022028. https://doi.org/10.1088/1757-899X/327/2/022028

17. Tomczyk J, Cink J, Kosucki A (2014) Dynamics of an overhead crane under a wind disturbance condition. Autom Constr 42: 100-111. https://doi.org/10.1016/j.autcon.2014.02.013

18. Ramli L, Mohamed Z, Efe MO, Lazim IM, Jaafar HI (2020) Efficient swing control of an overhead crane with simultaneous payload hoisting and external disturbances. Mech Syst Signal Process 135:106326. https://doi.org/10.1016/j. ymssp.2019.106326

19. Abdullahi AM, Mohamed Z, Selamat H, Pota HR, Zainal Abidin MS, Ismail FS, Haruna A (2016) Adaptive outputbased command shaping for sway control of a 3D overhead crane with payload hoisting and wind disturbance. Mech Syst Signal Process 98:157-172. https://doi.org/10.1016/j. ymssp.2017.04.034

20. Tang R, Huang J (2016) Control of bridge cranes with distributed-mass payloads under windy conditions. Mech Syst Signal Process 72-73:409-419. https://doi.org/10. 1016/j.ymssp.2015.11.002

21. Starosta R, Sypniewska-Kamińska G, Awrejcewicz J (2019) Plane motion of a rigid body suspended on nonlinear springdamper. In: Adrianov I, Manevich A, Mikhlin Y, Gendelman O (eds) Problems of nonlinear mechanics and physics of materials. Springer, Cham, pp 157-170

22. Maliki O, Anozie V (2018) On the stability analysis of a coupled rigid body. Appl Math 9:210-222. https://doi.org/ 10.4236/am.2018.93016

23. Starosta R, Sypniewska-Kamińska G, Awrejcewicz J (2012) Asymptotic analysis of kinematically excited dynamical systems near resonances. Nonlinear Dyn 68:459-469. https://doi.org/10.1007/s11071-011-0229-6

24. Starosta R, Sypniewska-Kamińska G, Awrejcewicz J (2011) Parametric and external resonances in kinematically and externally excited nonlinear spring pendulum. Int J Bifurc Chaos 21(10):3013-3021. https://doi.org/10.1142/S02181 27411030313

25. Awrejcewicz J, Starosta R, Sypniewska-Kamińska G (2013) Asymptotic analysis of resonances in nonlinear vibrations of the 3-dof pendulum. Differ Equ Dyn Syst 21:123-140. https://doi.org/10.1007/s12591-012-0129-3

26. Awrejcewicz J, Starosta R, Sypniewska-Kamińska G (2016) Stationary and transient resonant response of a spring pendulum. Proc IUTAM 19:201-208. https://doi.org/10.1016/j. piutam.2016.03.026

27. Puzyrov V, Awrejcewicz J (2018) Asymptotical stability of the motion of mechanical systems with partial energy dissipation. Nonlinear Dyn 91:329. https://doi.org/10.1007/ s11071-017-3872-8

28. Cekus D, Kwiaton P, Geisler T (2019) Analysis of the movement of the load during the interaction of wind force. In: 15th conference on dynamical systems theory and applications DSTA 2019. Abstracts: 246

29. Dong GH, Xu TJ, Zhao YP, Li YC, Gui FK (2010) Numerical simulation of hydrodynamic behavior of gravity cage in irregular waves. Aquac Eng 42:90-101. https://doi. org/10.1016/j.aquaeng.2009.12.004
30. Scheck F (2010) The mechanics of rigid bodies. Mechanics: from Newton's laws to deterministic chaos, 5th edn. Springer, Berlin, pp 187-240

31. Strzalko J, Grabski J, Perlikowski P, Stefanski A, Kapitaniak T (2009) General motion of a rigid body. Dynamics of gambling: origins of randomness in mechanical systems. Springer, Berlin, pp 23-39

32. Moon F (2008) Applied dynamics. With applications to multibody and mechatronic systems. Wiley-VCH Verlag GmbH Co, KGaA, Weinheim

33. Jaskot A, Posiadała B, Śpiewak S (2017) Dynamics modelling of the four-wheeled mobile platform. Mech Res Commun 83:58-64. https://doi.org/10.1016/j.mechrescom.2017.05.007

34. Posiadała B, Waryś P, Cekus D, Tomala M (2013) The dynamics of the forest crane during the load carrying. Int J Struct Stab Dyn 13:1-9. https://doi.org/10.1142/s0219455413400130

35. Awrejcewicz J (2012) Classical mechanics. Dynamics. Springer, New York

36. Cekus D, Gnatowska R, Kwiatoń P (2019) Impact of wind on the movement of the load carried by rotary crane. Appl Sci 9:3842. https://doi.org/10.3390/app9183842

37. Cekus D, Gnatowska R, Kwiatoń P, Sofer M (2019) Simulation research of a wind turbine using SolidWorks software. J Phys Conf Ser 1398:012001. https://doi.org/10. 1088/1742-6596/1398/1/012001

38. Cekus D, Kwiaton P (2020) Method of determining the effective surface area of a rigid body under wind disturbances. Arch Appl Mech. https://doi.org/10.1007/s00419020-01753-9

39. Kazakoff AB, Karaivanov D, Troha S (2007) Crane dynamics in a vertical base plane. C R Acad Bulgare Sci Sci Math Nat 60(10):1077-1084

40. Devenport W, Brown K, Borgoltz A et all (2018) Advanced wind tunnel boundary simulation for kevlar wall aeroacoustic wind tunnels. In: NATO STO symposium AVT-284, April 2018, Turin, Italy, pp. 10-1-10-12

41. Dassault Systems Solidworks Corporation (2014) SolidWorks 2014. Solidworks Motion, Waltham, p 2014

42. Gnatowska R, Sosnowski M, Uruba V (2017) CFD modelling and PIV experimental validation of flow fields in urban environments. E3S Web Conf 14:01034. https://doi. org/10.1051/e3sconf/20171401034

43. Nardone P, Koll K (2018) Velocity field and drag force measurements of a cube and a hemisphere mounted on an artificial bed surface roughness. E3S Web Conf 40:05022. https://doi.org/10.1051/e3sconf/20184005022

44. Cieśliński A, Prym W, Stajuda M, Witkowski D (2016) Investigation on aerodynamics of super-effective car for drag reduction. Mech Mech Eng 20:295-308

45. Posiadała B, Skalmierski B, Tomski L (1990) Motion of the lifted load brought by a kinematic forcing of the crane telescopic boom. Mech Mach Theory 25:547-556. https:// doi.org/10.1016/0094-114X(90)90068-U

46. Windfinder (2020) https://www.windfinder.com/. Accessed 11 Feb 2020

Publisher's Note Springer Nature remains neutral with regard to jurisdictional claims in published maps and institutional affiliations. 